\title{
Comparison of Sensory Processing and Semantic Differentiation in Peoples with Schizophrenia, Multiple Sclerosis and Alzheimer's Disease
}

\author{
Jahan Sadat Asadi Bijaeyeh" ${ }^{*}$, Hosein Ghamari Givi², Ali Sheykholeslami ${ }^{3}$ \\ ${ }^{1}$ Educated of MA, Rehabilitation Counseling, Faculty of Education and Psychology, University of Mohaghegh Ardabili, Ardabil, Iran \\ ${ }^{2}$ Professor, Faculty of Education and Psychology, University of Mohaghegh Ardabili, Ardabil, Iran \\ ${ }^{3}$ Assistant Professor, Faculty of Education and Psychology, University of Mohaghegh Ardabili, Ardabil, Iran \\ Email: *asadijahan70@gmail.com
}

How to cite this paper: Bijaeyeh, J.S.A., Givi, H.G. and Sheykholeslami, A. (2017) Comparison of Sensory Processing and Semantic Differentiation in Peoples with Schizophrenia, Multiple Sclerosis and Alzheimer's Disease. International Journal of Clinical Medicine, 8, 257-264.

https://doi.org/10.4236/ijcm.2017.84025

Received: January 4, 2017

Accepted: April 27, 2017

Published: April 30, 2017

Copyright $\odot 2017$ by authors and Scientific Research Publishing Inc. This work is licensed under the Creative Commons Attribution International License (CC BY 4.0).

http://creativecommons.org/licenses/by/4.0/

\begin{abstract}
Aim: The purpose of this study was comparison of sensory processing and semantic differentiation in patients with schizophrenia, multiple sclerosis (MS) and Alzheimer's disease. Method: Our research method was causal- comparative. Statistical population were patients with schizophrenia and patients with multiple sclerosis and Alzheimer's disease that are kept by formal caregivers in welfare centers in Guilan or by informal caregivers in families in Rasht city of Guilan province in Iran. 45 persons with MS, Alzheimer's disease and schizophrenia (in each group 15 persons) were randomly selected by accessible sampling method in 2014. Then, subjects were asked to response to sensory profile questionnaires to measure of sensory processing and ozgood semantic differentiation questionnaires to measure of semantic differentiation, then raw data were analyzed by multiple analyses of variance with using of spss $_{16}$ software. Results: $P$ value less than 0.05 , namely $p<0.05$ was considered as significant. The result showed that there were significant differences between sensory processing and semantic differentiation in patients. Sensory processing of Alzheimer $($ mean $=48.80 \mathrm{cl} 95 \%=45.10-52.49, \mathrm{p}=0.001<0.01$ ), had the maximum mean in three groups. Semantic differentiation of Alzheimer (mean $=$ $26.26 \mathrm{cl} 95 \%=23.71-28.82, \mathrm{p}=0.341>0.05$ ), had the maximum mean in three groups. Discussion and Conclusion: Because sensory processing and semantic differentiation aren't in a desirable condition in patients with schizophrenia, so it is necessary that the people who are at high risk of developing the disease or the initial stages of the disease, must be acted to improve their sensory processing and semantic differentiation.
\end{abstract}

\section{Keywords}

Schizophrenia, Multiple Sclerosis, Alzheimer, Sensory Processing, 
Semantic Differentiation

\section{Introduction}

Criterion B for schizophrenia gets more attention in DSM-5: "Level of functioning... is markedly below the level achieved prior to the onset". This is not a criterion for schizoaffective disorder (This is apparently unchanged from DSM4).

American Multiple Sclerosis Association [1] [2] see that Multiple sclerosis is an immune mediated process where an abnormal response puts the immune system against the central nervous system including the brain, spinal cord and optic nerves.

Alzheimer's disease or senile dementia is a progressive and debilitating chronic brain disorder, that is associated with profound effects on memory, intelligence and ability to care for themselve, and a defect in speech, motor activity, recognition of landscapes and familiar peoples or dysfunction in planning, innovation, organizing and abstract reasoning. diagnosing a people with Alzheimer's disease or the likelihood of developing Alzheimer's disease in elderly person is fearful for her or his relatives and carers [1] [3]. Usually "memory disorder", is the first symptom that arises.

Memory refers to recollection something from past and it is usually done consciously. Perhaps, sensory processing is the most essential componet of psychological, that forms the base of how people perceiving and reacting to environmental stimuli. New evidence shows that people, process the sensory information, in different ways. This means that some people are more sensitive than others to have sensory information [4] [5].

In a study by [6] under the title of "sensory processing in Schizophrenia; missing and avoiding information", three groups of people, first group people with schizophrenia, second, patients with bipolar disorder, third, normal people as control group, were compared on basis of a four components model of adult sensory profile with sensory sensitivity, sense avoid, low registration and sense searching variables that are described as behavioral responses to sense. In compare with normal group, all the two groups of patients with schizophrenia and bipolar disorder, had high score in sense avoid. Schizophrenia group had higher score in low registration and lower score in sense searching rather than healthy group. There were not any differences between the two groups of schizophrenia and bipolar disorder. Cording to the result of this research, patients with schizophrenia have desire to lose of available sensitive stimuli. When drivers actually appear, they are often avoided.

Initial descriptions of sensory sensitivity, McGhie \& Chapman [7] about attention deficit in patients with schizophrenia, including some personal reports, that describe the noises loudness, color brightness, distraction and disorganization in patient. Sensory gate insufficiency, that is measured by pre-trauma and 
latent inhibition such as techniques, also denotes the inability to filter out irrelevant information in this disorder. But Brown \& et al. [8] in their studies didn't find any meaningful differences between patients with schizophrenia, patients with bipolar disorders and normal people, in view point of sensory sensitivity. But the avoidance of feelings in people with schizophrenia and bipolar disorder was higher than normal. The schizophrenic patients frequently fail to response and ascribe meaning to stimuli. Their performance in reaction time tasks is an example of slowed response in schizophrenia. Return responses (the urge to go back to previous responses) can also be another example of low sensory registration in patients with schizophrenia. In connection with sense searching Brown \& et al. (Ghamari and Bashar poor, 2009), concluded that schizophrenia and bipolar disorder groups were significantly obtained lower scores in sense search. According to the results, since the extreme sensitivity and inhibition to sensory stimuli and also impairment in social skill which is the result of sensory pro- cessing disorder, is a very important aspect of schizophrenia and partly to major depressive disorder, therefore, identifying the style of sensory processing in patients with these disorders, can help to precise identify of impairment.

Rotenberg, quoted by [9] in a study on patients with schizophrenia showed that, cognitive impairment and inability to make appropriate use of past information, are connected with perceptual input or information processing and formation of signs that need to the left hemisphere activity.

Mehrinejad et al. [10] write that several studies have shown that the style of repressive character, negative emotions, inability to talk about feeling, over assimilation and hysteric characteristics with a weaker immune system and emotions expression and thoughts depended on excitement, are related to immune system performance improvement.

In a study by [11] under the title of "Sensory symptoms of multiple sclerosis: a hidden reservoir of morbidity, the following results reports: Sensory symptoms were more common in MS patients than in controls, and differed in severity and quality. There was however a strong correlation between the total number of sensory symptoms reported and the presence of disability in the MS patients. Conclusions: Sensory symptoms are common in MS patients. Pain syndromes, transient neurologic events, Lhermitte's phenomenon (to feel an electric shock symptom in the arms and legs downward by shaking and moving the neck), fatigue, respiratory symptoms and vertigo were present significantly more frequently in patients with MS than in a control population and contributed to subjective morbidity. Future clinical trials assessing therapy in MS might include sensory symptoms as secondary endpoints to capture this "hidden reservoir" of disease morbidity.

\section{Research Hypotheses}

Sensory processing in patients with schizophrenia and multiple sclerosis (ms) is different. 
Sensory processing in patients with schizophrenia and Alzheimer's is different.

Sensory processing in patients with multiple sclerosis (MS) and Alzheimer's is different. Semantic differentiation in patients with schizophrenia and multiple sclerosis (ms) is different.

Semantic differentiation in patients with schizophrenia and Alzheimer's is different.

Semantic differentiation in patients with multiple sclerosis (MS) and Alzheimer's is different.

\section{Methods}

Our research method was causal-comparative. Statistical population were patients with schizophrenia in Mirzakochak mental hospital and patients with multiple sclerosis and Alzheimer's disease that are kept by formal caregivers in welfare centers or by informal caregivers in families in Rasht city of Guilan province in Iran. 45 persons with MS, Alzheimer's disease and schizophrenia (in each group 15 persons) were randomly selected by accessible sampling method in 2014. Disease is independent variable and sensory processing and semantic differentiations are dependent variables. Then, subjects were asked to response to sensory profile questionnaires to measure of Sensory processing memory and to ozgood semantic differentiation questionnaire to measure of Semantic differentiating processing. This test is made after extensive research and application of factor analysis by Ozgood. This feature is made of 10 contradictory attributes and the participants will be asked to describe themselves based on 10 attributes. In this method Ozgood measures the emotional sense of the feelings against the words. The subject must score himself (or herself) with these ten characters, for example (Active-passive, quiet-restive) on a 7-points Likertscale [12]. Coefficient of Cronbach's Alpha of this test is 0.85 . Coefficient of internal consistency of subscales of sensory processing test were reported between 0.60 to 0.78 and Cronbach's Alpha coefficient of this test for total scale is 0.87 and for subscales of low registration, sense searching, sensory sensitivity and sense avoiding are as $0.72,0.65,0.75$ and 0.71 [13]. Then raw data were analyzed by multiple analyses of variance (MANOVA) with using of spss $_{16}$ software.

\section{Results}

Results of Table 1: Given that semantic differentiation mean of schizophrenia is 23.93 and multiple sclerosis is 26.20 and Alzheimer is 26.26 (maximum in three groups).

Results of Table 2: Given that total sensory processing mean of schizophrenia patient is 37 and multiple sclerosis is 37.40 and Alzheimer is 48.80 (maximum in three groups).

Results of Table 3: shows that for example low registration variable mean of schizophrenia is 9.20 and multiple sclerosis is 8.20 and Alzheimer's disease is 
Table 1. Descriptive information about semantic differentiation in the three examined groups.

\begin{tabular}{|c|c|c|c|c|c|c|}
\hline \multirow{2}{*}{ Variables } & \multirow{2}{*}{$\begin{array}{l}\text { Disease } \\
\text { groups }\end{array}$} & \multirow{2}{*}{ Frequency } & \multirow{2}{*}{ Mean } & \multirow{2}{*}{$\begin{array}{c}\text { Std. } \\
\text { Deviation }\end{array}$} & \multicolumn{2}{|c|}{$\begin{array}{c}95 \% \text { confidence } \\
\text { interval }\end{array}$} \\
\hline & & & & & $\begin{array}{l}\text { Lower } \\
\text { bound }\end{array}$ & $\begin{array}{l}\text { Upper } \\
\text { bound }\end{array}$ \\
\hline \multirow{3}{*}{$\begin{array}{l}\text { Total semantic } \\
\text { differentiation }\end{array}$} & Schizophrenia & 15 & $23 / 93$ & $1 / 265$ & $21 / 38$ & $26 / 48$ \\
\hline & $\begin{array}{l}\text { Multiple } \\
\text { sclerosis }\end{array}$ & 15 & $26 / 20$ & $1 / 265$ & $23 / 64$ & $28 / 75$ \\
\hline & Alzheimer & 15 & $26 / 26$ & $1 / 265$ & $23 / 71$ & $28 / 82$ \\
\hline
\end{tabular}

Table 2. Descriptive information about sensory processing in the three examined groups.

\begin{tabular}{|c|c|c|c|c|c|c|}
\hline \multirow{2}{*}{ Variables } & \multirow{2}{*}{ Disease groups } & \multirow{2}{*}{ Frequency } & \multirow{2}{*}{ Mean } & \multirow{2}{*}{$\begin{array}{c}\text { Std. } \\
\text { Deviation }\end{array}$} & \multicolumn{2}{|c|}{$\begin{array}{c}95 \% \text { confidence } \\
\text { interval }\end{array}$} \\
\hline & & & & & $\begin{array}{l}\text { Lower } \\
\text { bound }\end{array}$ & $\begin{array}{l}\text { Upper } \\
\text { bound }\end{array}$ \\
\hline \multirow{3}{*}{$\begin{array}{c}\text { Total } \\
\text { sensory } \\
\text { processing }\end{array}$} & Schizophrenia & 15 & 37 & $1 / 83$ & $33 / 30$ & $40 / 69$ \\
\hline & $\begin{array}{l}\text { Multiple } \\
\text { sclerosis }\end{array}$ & 15 & $37 / 40$ & $1 / 83$ & $33 / 70$ & $41 / 09$ \\
\hline & Alzheimer & 15 & $48 / 80$ & $1 / 83$ & $45 / 10$ & $52 / 49$ \\
\hline
\end{tabular}

Table 3. Descriptive information about the components of sensory processing in the three examined groups.

\begin{tabular}{cccccc}
\hline \multirow{2}{*}{$\begin{array}{c}\text { variables } \\
\text { Low }\end{array}$} & Disease groups & Frequency & Mean & $\begin{array}{c}\text { Std. } \\
\text { Deviation }\end{array}$ & $\begin{array}{c}\text { Std. Error } \\
\text { Mean }\end{array}$ \\
\hline $\begin{array}{c}\text { Registration } \\
\text { Schizophrenia }\end{array}$ & Multiple sclerosis & 15 & $9 / 20$ & $2 / 93$ & $0 / 76$ \\
Sensory & Alzheimer's disease & 15 & $15 / 87$ & $2 / 85$ & $0 / 80$ \\
sensitivity & Schizophrenia & 15 & $8 / 40$ & $3 / 08$ & $0 / 73$ \\
Multiple sclerosis & 15 & $9 / 60$ & $3 / 04$ & $0 / 80$ \\
Sensory & Alzheimer's disease & 15 & $10 / 47$ & $2 / 95$ & $0 / 76$ \\
avoidance & Schizophrenia & 15 & $8 / 47$ & $3 / 56$ & $0 / 92$ \\
& Multiple sclerosis & 15 & 7 & $3 / 12$ & $0 / 80$ \\
& Alzheimer's disease & 15 & $12 / 93$ & $2 / 31$ & $0 / 60$ \\
& Schizophrenia & 15 & $10 / 93$ & $2 / 89$ & $0 / 75$ \\
\hline \multirow{2}{*}{$\begin{array}{c}\text { Sense searching } \\
\text { Multiple sclerosis }\end{array}$} & Alzheimer's disease & 15 & $15 / 40$ & $1 / 30$ & $0 / 89$ \\
& & 15 & $12 / 47$ & $3 / 46$ & $0 / 33$ \\
\hline
\end{tabular}

\subsection{7 and so on.}

Results of Table 4: Given that significance level of $p=0.47>0.05$, variances are equal.

The result of Table 5: In firstrow, given that significant level equal to $\mathrm{p}=$ $0.001<0.01$, so there is a significant difference between the groups in sensory processing. 
Table 4. Levin test for sensory processing.

\begin{tabular}{ccccc}
\hline Dependent Variable & F & Df1 & Df2 & sig \\
\hline Sensory processing & $3 / 28$ & 2 & 42 & $0 / 47$ \\
Semantic differentiation & $0 / 867$ & 2 & 42 & $0 / 47$ \\
\hline
\end{tabular}

Table 5. Results of the multivariate analysis of sensory processing.

\begin{tabular}{cccccccc}
\hline Source & $\begin{array}{c}\text { Depended } \\
\text { variable }\end{array}$ & $\begin{array}{c}\text { Sum of } \\
\text { squares }\end{array}$ & $\begin{array}{c}\text { Degrees } \\
\text { of } \\
\text { freedom } \\
\text { (d.f) }\end{array}$ & $\begin{array}{c}\text { Squares } \\
\text { mean }\end{array}$ & F & sig & $\begin{array}{c}\text { Partial } \\
\text { Eta } \\
\text { Squared }\end{array}$ \\
\hline \multirow{2}{*}{ Groups } & $\begin{array}{c}\text { Sensory } \\
\text { processing } \\
\text { Semantic }\end{array}$ & $1346 / 8$ & 2 and 42 & $673 / 4$ & $13 / 379$ & $0 / 000$ & $0 / 389$ \\
& & & & & & & \\
differentiation & $52 / 933$ & 2 and 42 & $26 / 467$ & $1 / 102$ & $0 / 34$ & $0 / 05$ \\
\hline
\end{tabular}

In second row, given that significant level equal to $\mathrm{p}=0.341>0.05$, so there isn't a significant difference between the groups in semantic differentiation.

\section{Discussion and Conclusions}

Average sensory processing and average semantic differentiation are different in three groups of patients with schizophrenia, multiple sclerosis and patients with Alzheimer. An obvious conclusion is that the sensory processing in patients with multiple sclerosis and Alzheimer's is better than the group with schizophrenia. This issue is consistent with the inhibition reaction by patients with schi-zophrenia that cited by [5] in literature. Totally patients with Alzheimer's disease had significantly better performance in sensory processing. Patients with schizophrenia had lower performance than the other two groups. The semantic differentiation in patients with multiple sclerosis and Alzheimer's is better than the group with schizophrenia. This issue is consistent with the studies of [10] [12] [13] in literature. Totally patients with Alzheimer's disease had better performance in semantic differentiation. Patients with schizophrenia had lower performance than the other two groups.

One of the major limitations in sample size is illiterate or low literacy people which make it difficult to gather information and need to give sufficient information and required training to individuals to fill the questionnaires which are time consuming. In the present study variables such as gender, marital status, education, and the severity and duration of illness are not included.

Given that sensory processing in patients with Alzheimer was better than the other tow groups, therefore, it is better to use of sensory processing and its enhancement to treatment and rehabilitation of these people, it means that must be used of sensory processing to compensate other memories.

Because sensory processing isn't in a desirable condition in patients with schizophrenia and multiple sclerosis (MS), so it is necessary that the people who are at high risk of developing the disease or the initial stages of the disease, must 
be acted to improve their sensory processing.

Given that semantic differentiation in patients with Alzheimer was better than the other tow groups, therefore, it is better to use of semantic differentiation and its enhancement to treatment and rehabilitation of these people, it means that must be used of semantic differentiation to compensate other memories.

Because semantic differentiation isn't in a desirable condition in patients with schizophrenia, so it is necessary that the people who are at high risk of developing the disease or the initial stages of the disease, must be acted to improve their semantic differentiation.

\section{References}

[1] Givi, G., Shykholeslami, H., AsadiBijaeyeh, A. and Sadat, J. (2016) Comparison of Sensory Processing and Semantic Differentiation in Peoples with Schizophrenia, Multiple Sclerosis and Alzheimer's Disease. IIOABJ, 7, 77-83.

[2] Yang, M. (2013) dsm-5: Schizophrenia. 28 August. www.mariayang.org

[3] American National Multiple Sclerosis Society (2014) What Is MS, Share.net, MSAA, Improving Lives Today! http://mymsaa.org/

[4] Khatoni, M. and Zahari, S. (2010) Communication Problems in Elderly Patients with Alzheimer's Disease and Primary Caregivers. Journal of Elderly, 5, 36-42.

[5] Ghamari, H. and Bashar Poor, S. (1388) The Study of Sensory and Semantic Information Processing in Schizophrenia, Major Depressive Disorder and Normal. Journal of Clinical Psychology, 2, 17-25.

[6] Beatty, W.W., Goodkin, D.E., Monson, N., Beatty, P.A. and Hertsgaurd, D. (1988) Anterograde and Retrograde Amnesia in Patients with Chronic Progressive Multiple Sclerosis. Archives of Neurology, 45, 611-619. https://doi.org/10.1001/archneur.1988.00520300029013

[7] Gardner, A.P.W. and Gibson, S.L.M. (1989) Semantic Differential Techniques in the Identification of Individuals Assessment of Health State: A Case Study of a Patient within a Homoeopathic Regime. Counselling Psychology Quarterly, 2, 273-288. https://doi.org/10.1080/09515078908256683

[8] Adams, J., Faux, S.F., Nestor, P.G., Shenton, M., Marcy, B., Smith, S. and McCarley, R.W. (1993) ERP Abnormalities during Semantic Processing in Schizophrenia. Schizophrenia Research, 10, 247-257.

[9] Pekkaonen, E., Jousmaki, V., Kononen, M., Reinikainen, K. and Partanen, J. (1994) Auditory Sensory Memory Impairment in Alzheimer's Disease: An Event-Related Potential Study. Neuroreport, 5, 2537-2540.

[10] Gourovitch, M.L., Goldberg, T.E. and Weinberger, D.R. (1996) Verbal Fluency Deficits in Patients with Schizophrenia: Semantic Fluency Is Differentially Impaired as Compared with Phonologic Fluency. Neuropsychology, 10, 573-577. https://doi.org/10.1037/0894-4105.10.4.573

[11] Graham, K., Hodges, S. and John, R. (1997) Differentiating the Roles of the Hippocampus Complex and the Neocortex in Long-Term Memory Storage: Evidence from the Study of Semantic Dementia and Alzheimer's Disease. Neuropsychology, 11, 77-89. https://doi.org/10.1037/0894-4105.11.1.77

[12] Hodges, J.R., Patterson, K., Ward, R., Garrard, P., Bak, T., Perry, R. and Gregory, C. (1999) The Differentiation of Semantic Dementia and Frontal Lobe Dementia (Temporal and Frontal Variants of Front Temporal Dementia) from Early Alzheimer's Disease: A Comparative Neuropsychological Study. Neuropsychology, 13, 
31-40. https://doi.org/10.1037/0894-4105.13.1.31

[13] Jessen, F., Kucharski, C., Fries, T., Papassotiropoulos, A., Hoenig, K., Maier, W. and Heun, R. (2001) Sensory Gating Deficit Expressed by a Disturbed Suppression of the P50 Event-Related Potential in Patients with Akzheimer's Disease. The American Journal of Psychiatry, 158, 1319-1321.

https://doi.org/10.1176/appi.ajp.158.8.1319

\section{Scientific Research Publishing}

Submit or recommend next manuscript to SCIRP and we will provide best service for you:

Accepting pre-submission inquiries through Email, Facebook, LinkedIn, Twitter, etc. A wide selection of journals (inclusive of 9 subjects, more than 200 journals)

Providing 24-hour high-quality service

User-friendly online submission system

Fair and swift peer-review system

Efficient typesetting and proofreading procedure

Display of the result of downloads and visits, as well as the number of cited articles Maximum dissemination of your research work

Submit your manuscript at: http://papersubmission.scirp.org/

Or contact ijcm@scirp.org 